\title{
Optimization of Stroke Rehabilitation Hand Component of 3D Printing With Taguchi Method Approach
}

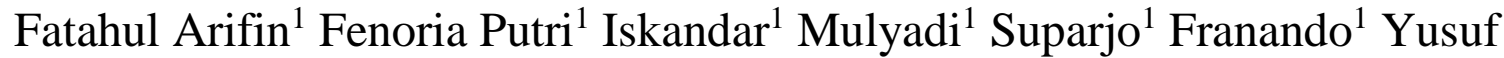 \\ Dewantoro Herlambang, ${ }^{2, *}$
}

\author{
${ }^{1}$ Mechanical Engineering Department, Politeknik Negeri Sriwijaya, Palembang, 30154, Indonesia \\ ${ }^{2}$ Mechanical Engineering Department, Politeknik Negeri Semarang, Semarang, 50275, Indonesia \\ (*) Corresponding author: masyusufdh@polines.ac.id
}

\begin{abstract}
3D Printing commonly is known as additive manufacturing. It works by adding layer by layer resulting in a three dimensional shape. Using color change filament materials are safe to use for medical purposes. The parameters used in this study are layer height, print speed and print temperature. The most percentage of contributions is affected in the taguchi experiment of dimensional accuracy namely; layer height (51.196\%), and Brinell Hardness Number namely; print speed $(61,097 \%)$. The optimal parameters resulting of the taguchi experiment's dimensional accuracy are layer height $(0,10 \mathrm{~mm})$, print speed $(40 \mathrm{~mm} / \mathrm{s})$ and print temperature $\left(195^{\circ} \mathrm{C}\right)$. The optimal parameters resulting of Brinell Hardness Number are layer height $(0,10 \mathrm{~mm})$, print speed $(20 \mathrm{~mm} / \mathrm{s})$ and print temperature $\left(205^{\circ} \mathrm{C}\right)$.
\end{abstract}

Keywords: 3D Printing, layer height, print speed, dimensional

\section{INTRODUCTION}

The causes of stroke are different among the countries, however, the largest are developed countries, especially Russia, Eastern European countries, and East Asian countries in 2013. The ranging is from $11.6 \%$ to $12.7 \%$ in North Korea, Macedonia, Bulgaria, and Georgia, while from $8.4 \%$ to $9.7 \%$ in China and Indonesia [1]. Stroke patients are required to follow rehabilitation programs, which consist of repetitive task practice (RTP) in order to restore their hand function [2]. Rehabilitation is a program set to people with physical disabilities or chronic diseases, so they can to live or work with their capacity [3]. Therefore, , robotic devices such as exoskeletons are use to assist with repetitive hand movements as an alternative to physiotherapistassisted program [4]. These devices do not only to reduce the therapist workload, but also help to improve therapy conditions for the patients. Experimental studies have confirmed that the used of robotic systems for post stroke and post trauma physical therapy under doctor supervision improves motor functions of the patients [5].

The 3D printing is used produce the part with different way compare with the traditional manufacturing process. It can the physical realization of a 3D computer aided design (CAD) model by implementing the layer by layer addition of materials, thus producing a 3D physical object with the same structure as the digital model [6]. The 3D printing technology is attractive for many applications namely; the research field for prototyping or for a limited production of prototypes; (ii) in medicine to create 3D biomedical structures using digital models obtained with different medical imaging techniques ie. computer tomography, magnetic resonance imaging, ultrasound, prototyping industry and automotive part manufacturing [7]. Material of 3D printing is used additive processing, that are control with computer control. These objects is produced with a 3D modelling or other electronic data source. The Poly Lactic Acid (PLA) is most common 3D printed filament used in FDM machine. It is generally produced from PLA and a bio degradable filament. It is also very easy to print which doesn't require heated bed [8] then, it is also one of the semicrystalline thermoplastic that has been a growing potential in FDM filament material [9].

Before, we produce part that should know the parameters and the number of experiment needed can be considered as the best possible method to the 
problem in industrial [10]. The parameter design is an optimized part of the Taguchi method and is often used to improve the product and process design $[11,12]$ and the Taguchi method also is one of a design of experimental (DOE) that is to calculate a set of design variables in such a manner, then analyzed result with superior to all other possible design variants [13 and 14]. The purpose of this research is to obtain 3D printing product that is better in a size according to the design and strong structural.

\section{PART DESIGN AND ANALYSIS}

The material color change filament is used in this study that have performance similar with PLA. It is nontoxic, environment-friendly, and excellent printing performance. Then, printed into components using The 3D Printer Fused Deposition Modeling (FDM) with Cartesian type is used in this study. The shape and dimensions of the part are shown in figure 1 .

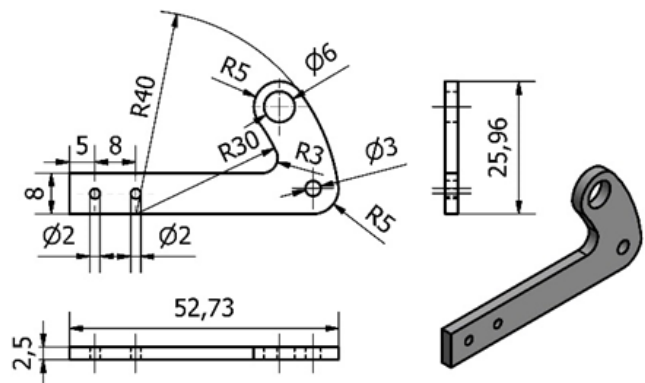

Figure 1. Dimensions of part

\subsection{Processing Window}

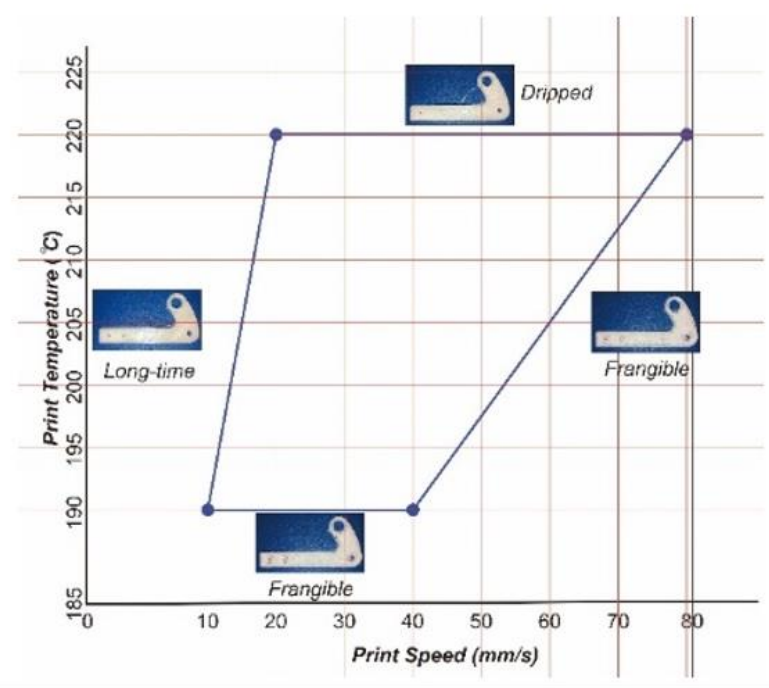

Figure 2. Print Temperature vs Print Speed

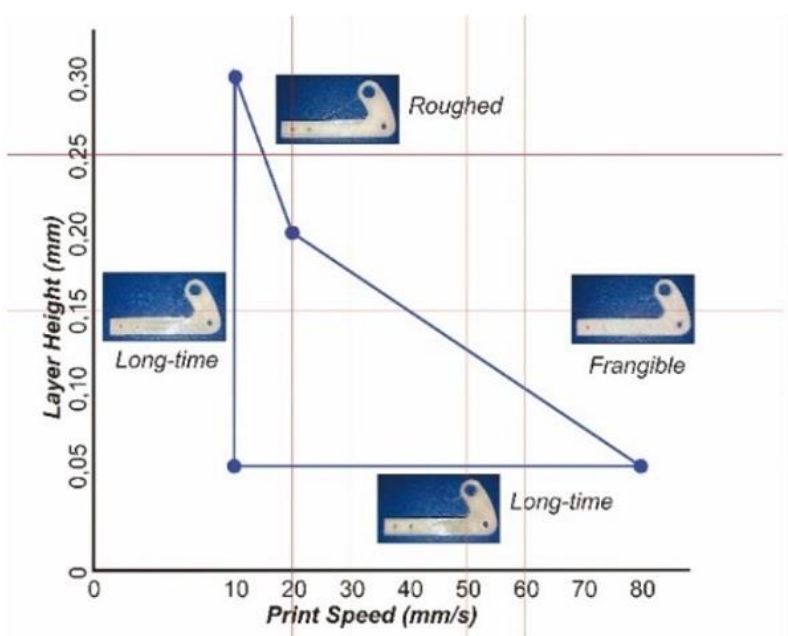

Figure 3. Layer Height vs Print Speed

By using a series of trial experiment is created processing window (Figure 2 and 3), that the result of is used to select parameters and level of Taguchi experiment. In this study we choose; Layer heights (LH) are $0.05 \mathrm{~mm}, 0.10 \mathrm{~mm}, 0.15 \mathrm{~mm}$; Print Speeds (PS) are $20 \mathrm{~mm} / \mathrm{s}, 30 \mathrm{~mm} / \mathrm{s}, 40 \mathrm{~mm} / \mathrm{s}$; and Print Temperature (PT) $195^{\circ} \mathrm{C}, 210^{\circ} \mathrm{C}, 215^{\circ} \mathrm{C}$

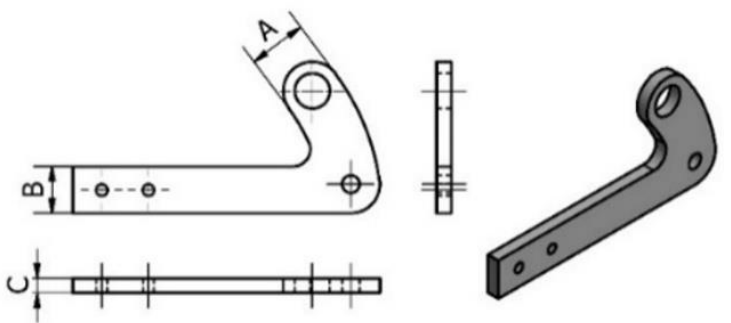

Figure 4. Dimensional accuracy

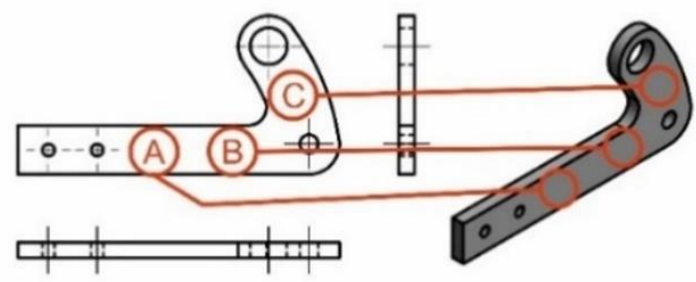

Figure 5. Hardness test area

The dimension accuracy (DA) is measured with the actual part reduced design part. The location of measurement shown in Figure 4. The dimensional accuracy (DA) of each dimension can be calculated by the following equation:

$$
\mathrm{DA}=\frac{\text { Actual Part-Design Part }}{\text { Design Part }} \times 100 \%
$$


where Design Part $(\mathrm{mm})$ is the design dimension and Actual Part ( $\mathrm{mm})$ is the dimension measured from the specimen or printing result from 3D Printer. The averaged dimensional accuracy of the measurements is calculated. Then, the hardness test is determined to get the strength of the structure of product. The Brinnell Hardness Number (HBN) is used in this study, then the position of measurement can be seen in Figure 5. The Brinell Hardness Number (BHN) can be calculated by the following equation:

$\mathrm{BHN}=\frac{2 \mathrm{P}}{\pi \times \mathrm{D}\left(\mathrm{D}-\sqrt{\mathrm{D}^{2}-\mathrm{dr}^{2}}\right)}$

Where Brinell Hardness Number (BHN), $\mathrm{P}(\mathrm{kg})$ is a load of indentor, $\mathrm{D}(\mathrm{mm})$ is diameter of indenter and $\mathrm{dr}$ $(\mathrm{mm})$ is result of indenter diameter on surface. The averaged brinell hardness number of the measurements is calculated.

\section{RESULT AND DISCUSSION}

\subsection{Dimensional Accuracy (DA) Result}

Dimensional Accuracy (DA) were considered as the performance quality characteristics with the concept of smaller the better. The dimensional accuracy of the nine runs can be seen in Table 1. The results indicated that the sixth run demonstrated the best performance.

Table 1. Results of the sum average of dimensional accuracy and the S/N ratio

\begin{tabular}{|c|c|c|c|c|c|c|c|c|}
\hline \multirow{2}{*}{$\begin{array}{l}\text { No. } \\
\text { Eks }\end{array}$} & \multirow{2}{*}{ LH $(\mathbf{m m})$} & \multirow{2}{*}{$\mathbf{P S}(\mathbf{m m} / \mathbf{s})$} & \multirow{2}{*}{ PT $\left({ }^{\circ} \mathrm{C}\right)$} & \multicolumn{3}{|c|}{ Dimensional Accuration (\%) } & \multirow{2}{*}{ Ave.DA } & \multirow{2}{*}{ S/N Ratio } \\
\hline & & & & $\mathbf{D A}_{1}$ & $\mathbf{D A}_{2}$ & $\mathrm{DA}_{3}$ & & \\
\hline 1 & 0.5 & 20 & 195 & 1,525 & 1,633 & 1,192 & 1,450 & $-3,227$ \\
\hline 2 & 0.5 & 30 & 205 & 0,917 & 1,492 & 0,783 & 1,064 & $-0,539$ \\
\hline 3 & 0.5 & 40 & 215 & 0,750 & 1,050 & 1,008 & 0,936 & 0,574 \\
\hline 4 & 0.1 & 20 & 205 & 0,475 & 0,758 & 0,550 & 0,594 & 4,519 \\
\hline 5 & 0.1 & 30 & 215 & 0,767 & 0,875 & 0,825 & 0,822 & 1,699 \\
\hline 6 & 0.1 & 40 & 195 & 0,392 & 0,258 & 0,375 & 0,342 & 9,328 \\
\hline 7 & 0.15 & 20 & 215 & 1,100 & 1,033 & 1,050 & 1,061 & $-0,514$ \\
\hline 8 & 0.15 & 30 & 195 & 0,467 & 0,508 & 0,633 & 0,536 & 5,417 \\
\hline 9 & 0.15 & 40 & 205 & 0,650 & 0,783 & 1,133 & 0,856 & 1,357 \\
\hline
\end{tabular}

Table 2. The ANOVA for Dimensional Accuration (DA)

\begin{tabular}{|l|c|c|c|c|c|c|}
\hline \multicolumn{1}{|c|}{ Factors } & & LH & PS & PT & Error & Total \\
\hline \multirow{3}{*}{ Sum of Factor Levels } & 1 & $-3,192$ & 0,778 & 11,517 & $-0,171$ & \\
\cline { 2 - 7 } & 2 & 15,546 & 6,577 & 5,338 & 8,275 & 18,614 \\
\cline { 2 - 7 } & 3 & 6,260 & 11,260 & 1,759 & 10,511 & \\
\hline Sum of Squares of Differences & & 526,688 & 165,431 & 146,212 & 190,428 & 1028,759 \\
\hline Degrees of Freedom & & 2 & 2 & 2 & 2 & 8 \\
\hline Percentage Contribution Ratio & & 51,196 & 16,081 & 14,212 & 18,510 & \\
\hline Cumulative Contribution Ratio & & 51,196 & 67,277 & 81,490 & 100 & \\
\hline Optimum Levels & & $\mathrm{A} 2$ & $\mathrm{~B} 3$ & $\mathrm{C} 1$ & & \\
\hline
\end{tabular}

The contributions of the factors are Layer Height $51,196 \%$, Print Speed 16,081\% and Print Temperature $14,212 \%$ as shown in Table 2. Layer Height is the dominant factor in the measuring dimensional accuracy on product part.
From the response graph Figure 6, the best parameter combination is able to be calculated by choosing the level with the highest value of each factor, and that is LH2PS3PT1 which corresponds to the Layer height $0.10 \mathrm{~mm}$, Print speed $40 \mathrm{~mm} / \mathrm{s}$, Print temperature $195^{\circ} \mathrm{C}$. 


\section{DIMENSIONAL ACCURATION (DA)}

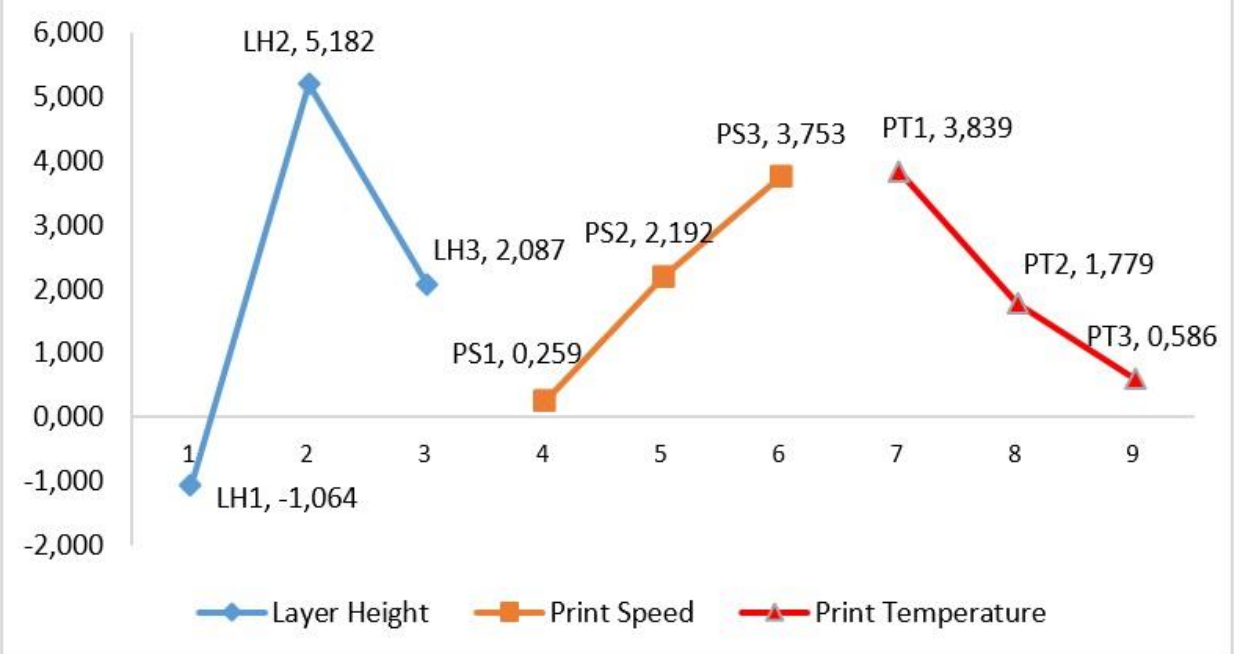

Figure 6. The Effect Plot for SN Ratios Dimensional Accuracy

\subsection{The Brinell Hardness Number Test}

The Brinell Hardness Number (BHN) were considered as the performance quality characteristics with the concept of larger the better. The BHN of the nine runs are listed in Table 3 . The results indicated that the fourth run demonstrated the best performance.

Table 3. Results of the sum average of hardness test and the $\mathrm{S} / \mathrm{N}$ ratio

\begin{tabular}{|c|c|c|c|c|c|c|c|c|}
\hline \multirow{2}{*}{$\begin{array}{l}\text { No. } \\
\text { Eks }\end{array}$} & \multirow{2}{*}{ LH (mm) } & \multirow{2}{*}{ PS $(\mathbf{m m} / \mathbf{s})$} & \multirow{2}{*}{ PT $\left({ }^{\circ} \mathrm{C}\right)$} & \multicolumn{3}{|c|}{$\mathrm{BHN}\left(\mathrm{Kg} / \mathrm{mm}^{2}\right)$} & \multirow{2}{*}{ Ave. BHN } & \multirow{2}{*}{ S/N Ratio } \\
\hline & & & & $\mathrm{BHN}_{1}$ & $\mathrm{BHN}_{2}$ & $\mathrm{BHN}_{3}$ & & \\
\hline 1 & 0.5 & 20 & 195 & 6,607 & 9,427 & 8,589 & 8,208 & 18,284 \\
\hline 2 & 0.5 & 30 & 205 & 7,021 & 7,987 & 7,871 & 7,626 & 17,646 \\
\hline 3 & 0.5 & 40 & 215 & 6,505 & 5,329 & 4,881 & 5,571 & 14,920 \\
\hline 4 & 0.1 & 20 & 205 & 11,710 & 12,026 & 11,169 & 11,635 & 21,315 \\
\hline 5 & 0.1 & 30 & 215 & 5,063 & 7,572 & 7,135 & 6,590 & 16,378 \\
\hline 6 & 0.1 & 40 & 195 & 5,452 & 4,574 & 4,532 & 4,853 & 13,720 \\
\hline 7 & 0.15 & 20 & 215 & 6,576 & 5,840 & 6,536 & 6,317 & 16,011 \\
\hline 8 & 0.15 & 30 & 195 & 4,366 & 5,372 & 6,043 & 5,261 & 14,420 \\
\hline 9 & 0.15 & 40 & 205 & 3,710 & 4,788 & 3,715 & 4,071 & 12,194 \\
\hline
\end{tabular}

These results in Table 4 show that the layer height $27.07 \%$, print speed $61.09 \%$, print temperature $7.08 \%$ as the influence factor for BHN. This proves that print significant parameters contribute to improving $\mathrm{BHN}$ in the process while print temperature only have small speed, layer height, and print temperature are the most effect towards the BHN.

Table 4. The ANOVA for Brinell Hardness Number (BHN)

\begin{tabular}{|c|c|c|c|c|c|c|}
\hline Factors & & LH & PS & PT & Error & Total \\
\hline \multirow{3}{*}{ Sum of Factor Levels } & 1 & 50,850 & 55,610 & 46,424 & 46,856 & \multirow{3}{*}{144,888} \\
\hline & 2 & 51,413 & 48,444 & 51,516 & 47,377 & \\
\hline & 3 & 42,625 & 40,833 & 47,308 & 50,655 & \\
\hline Sum of Squares of Differences & & 145,197 & 327,641 & 37,971 & 25,454 & 536,264 \\
\hline Degrees of Freedom & & 2 & 2 & 2 & 2 & 8 \\
\hline Percentage Contribution Ratio & & 27,076 & 61,097 & 7,081 & 4,747 & \\
\hline Cumulative Contribution Ratio & & 27,076 & 88,173 & 95,253 & 100 & \\
\hline Optimum Levels & & A2 & B1 & $\mathrm{C} 2$ & & \\
\hline
\end{tabular}




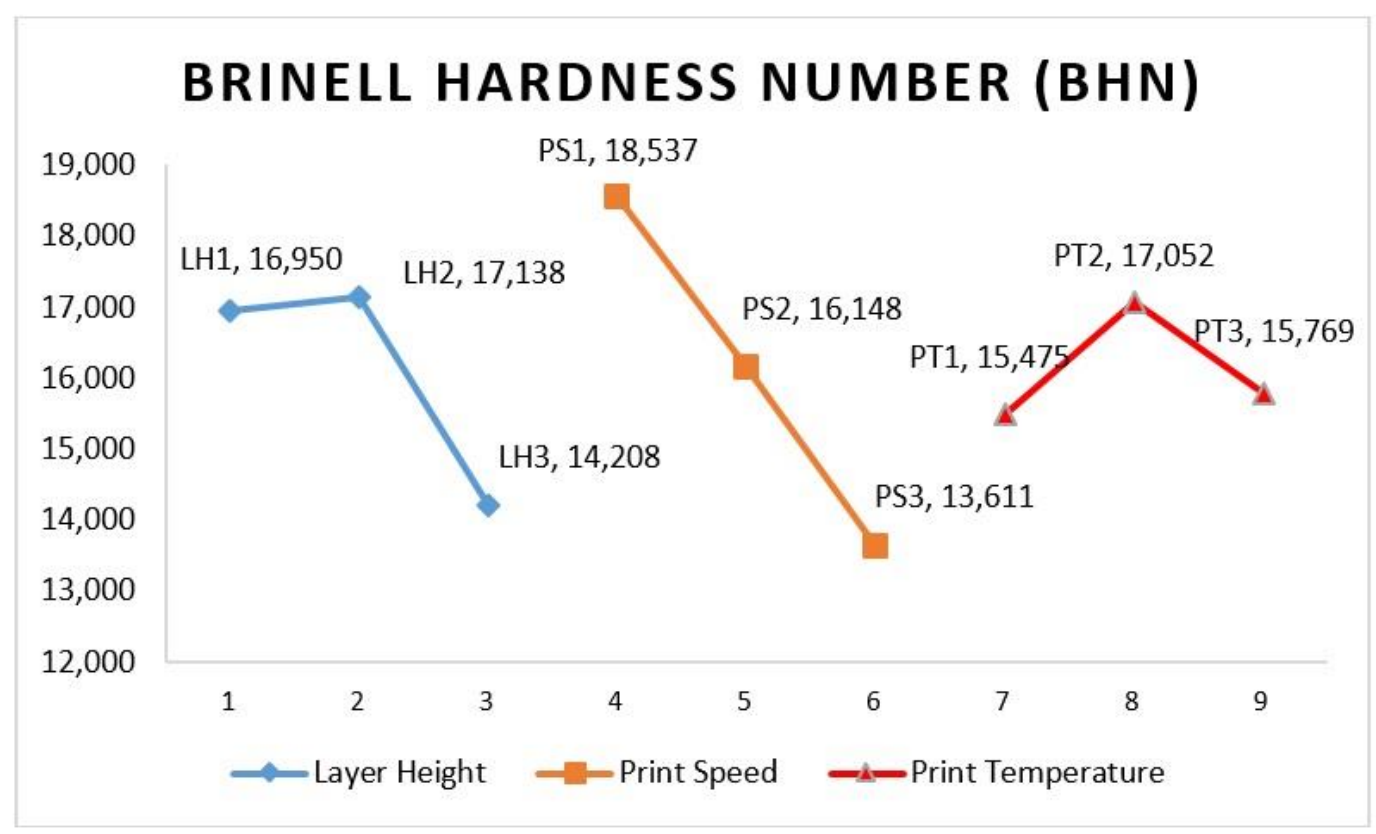

Figure 7. Main Effect Plot for SN Ratios Brinell Hardness Number

The best parameter combination is able to be calculated by choosing the level with the highest value of each factor, and that is LH2PS1PT2 which corresponds to the Layer height $0.10 \mathrm{~mm}$, Print speed $20 \mathrm{~mm} / \mathrm{s}$, Print temperature $205^{\circ} \mathrm{C}$ as can be seen in the response graph figure 5 .

Since, the result of the Taguchi experiment above is the optimal process parameters suggested from dimensional accuracy and brinell hardness number are shown in Table 5.

Table 5. Confirmation experiments for taguchi

\begin{tabular}{|c|c|c|c|c|}
\hline \multirow{2}{*}{ Method } & \multirow{2}{*}{ Responses } & \multirow{2}{*}{$\begin{array}{c}\text { Optimum } \\
\text { Levels }\end{array}$} & \multicolumn{2}{|c|}{$\begin{array}{c}\text { Average } \\
\text { Experimental } \\
\text { Values }\end{array}$} \\
\cline { 4 - 5 } & & $\begin{array}{c}\text { DA } \\
(\%)\end{array}$ & $\begin{array}{c}\mathbf{B H N} \\
\left(\mathbf{K g} / \mathbf{m m}^{2}\right)\end{array}$ \\
\hline Taguchi & $\begin{array}{c}\text { Dimensional } \\
\text { Accuracy }\end{array}$ & $\mathrm{A}_{2} \mathrm{~B}_{3} \mathrm{C}_{1}$ & 0,203 & 4,862 \\
\hline Taguchi & $\begin{array}{c}\text { Brinell } \\
\text { Hardness } \\
\text { Number }\end{array}$ & $\mathrm{A}_{2} \mathrm{~B}_{1} \mathrm{C}_{2}$ & 0,647 & 11,537 \\
\hline
\end{tabular}

\section{CONCLUSION}

In conclusion, dimensional changing occurs in all products 3D printing for many reasons. However, the question is how these defects can be reduced and which parameters are dominant in this process. However, it is significant to understand and calculate the cause and effect of these defects. Since, it will be improved completely by optimizing some process parameters using the Taguchi method. The current studies have obtained considerable results to know the relationship between them. Layer height, print speed, and print temperature are some of the major molding parameters influence the product dimensional changing. During the printing process, the dimension of product is very small, therefore, it is hard to ovoid to minimize the changing. Besides, measuring the BHN was not get accurate number, thus the error happens during the measuring process. The experimental results support the proposed approach which not only minimize the dimensional changing of the product of 3D printing process but also improves the quality of the hardness of product.

\section{ACKNOWLEDGMENT}

This work is supported by Ministry of Cultural and Education of Republic of Indonesia, Directoral of Vocational Higher Education, Politeknik Negeri Sriwijaya through Research Development Funding 2020

\section{REFERENCES}

[1] Feigin V. L. Norrving B. and Mensah G. A. Mensah. 2017. Global Burden of Stroke. Circulation Research 120(3):439-48.

[2] Rosenstein, L., Ridgel, A. L., Thota, A., Samame, B., and Alberts, J. L. 2008. Effects of Combined Robotic Therapy and Repetitive-Task Practice on Upper- Extremity Function in a 
Patient with Chronic Stroke. Am. J. Occup. Ther., 62(1), pp. 28-35.

[3] O’Driscoll, S. W., Giori, N. J. 2000. Continuous Passive Motion (CPM): Theory and Principles of Clincial Application. Journal of Rehabilitation Research and Development, 37(2).

[4] Maciejasz P., Eschweiler J., Gerlach H. K., Jansen T. A., and Leon H. S. 2014. A Survey on Robotic Devices for Upper Limb Rehabilitation. J. Neuroeng. Rehabil. 11(3), pp. 1-29.

[5] Cherian B., Clins D., and Vishakh K. R. 2018. Exo-Glove: A Soft Wearable Robotic Hand for Stroke Survivors International Research Journal of Engineering and Technology.

[6] Yaowen L. Xue L. Ahmed S. Weijie L. and Wen Q. 2019. Properties of 3D Printed Dough and Optimization of Printing Parameters. Innovative Food Science and Emerging Technologies 54(March):9-18.

[7] Chiulan I. Frone A. N. Brandabur C. and Panaitescu D. M. 2018. Recent Advances in 3D Printing of Aliphatic Polyesters. Bioengineering 5(1):1-18.

[8] Vikas, B., Hussain, M.M., and Reddy. C.S. 2019. "Optimization of 3D Printing Process Parameters of Poly Lactic Acid Materials by Fused Deposition Modeling Process.” 7(3):189-96.
[9] Tian X, Liu T, Yang C, Wang Q, Li D. Interface and performance of $3 \mathrm{D}$ printed continuous carbon fiber reinforced PLA composites. Composites Part A: Applied Science and Manufacturing. 2016; 88:198-205.

[10] Rosenstein, L., Ridgel, A. L., Thota, A., Samame, B., and Alberts, J. L., 2008, "Effects of Combined Robotic Therapy and Repetitive-Task Practice on Upper- Extremity Function in a Patient With Chronic Stroke," Am. J. Occup. Ther., 62(1), pp. 28-35.

[11] Wang M. W., Arifin F., Huang J. Y. 2019. Optimization of The Micro Molding of A Biconcave Structure. International Journal of Technology 10(2): 269-279.

[12] Wang M.W., Arifin F., Kuo H. L. 2019. Study on micromoulding of a high viewing angle LED lens. Plastics, Rubber and Composites, DOI: 10.1080/14658011.2019.1685803

[13] Surange, Vinod G., and Punit V Gharat. 2016. "Using Fused Deposition Modelling (FDM) Vinod." International Research Journal of Engineering and Technology (IRJET) 3(3):14036.

[14] Graf, W., Sickert J. U., Pannier, S., and Kaliske M. 2010. Robust Design with Uncertain Data and Response Surface Approximation. (May 2014):554-73 